\title{
PPARY agonist through the terminal differentiation phase is essential for adipogenic differentiation of fetal ovine preadipocytes
}

\author{
Yong Pu and Almudena Veiga-Lopez *
}

\author{
* Correspondence: veiga@msu.edu \\ Department of Animal Science, \\ Michigan State University, 474 S. \\ Shaw Lane Rm 1230 F, East Lansing, \\ Ml 48824, USA
}

\begin{abstract}
Background: Although the 3T3-L1 preadipocyte cell line represents an informative model for in vitro adipogenesis research, primary cultured cells are often needed to understand particular human or animal metabolic phenotypes. As demonstrated by in vitro cultured preadipocytes from large mammalian species, primary cultured cells require specific adipogenic differentiation conditions different to that of the 3T3-L1 cell line. These conditions are also species-specific and require optimization steps. However, efficient protocols to differentiate primary preadipocytes using alternative species to rodents are scarce. Sheep represent an amenable animal model for fetal biology and developmental origins of health and disease studies. In this work, we present with the first detailed procedure to efficiently differentiate primary fetal and adult ovine preadipocytes.
\end{abstract}

Methods: Fetal and adult ovine adipose and skin tissue harvest, preadipocyte and fibroblast isolation, proliferation, and standardization and optimization of a new adipogenic differentiation protocol. Use of commercial cell lines (3T3-L1 and NIH-3T3) for validation purposes. Oil red $O$ stain and gene expression were used to validate adipogenic differentiation. ANOVA and Fisher's exact test were used to determine statistical significance.

Results: Our optimized adipogenic differentiation method included a prolonged adipogenic cocktail exposure time from 2 to 8 days, higher insulin concentration, and supplementation with the peroxisome proliferator-activated receptor gamma (PPARY) agonist, rosiglitazone. This protocol was optimized for both, fetal and adult preadipocytes.

Conclusions: Our protocol enables successful adipogenic differentiation of fetal and adult ovine preadipocytes. This work demonstrates that compared to the 3T3-L1 cell line, fetal ovine preadipocytes require a longer exposure to the differentiation cocktail, and the need for IMBX, dexamethasone, and/or the PPARY agonist rosiglitazone through the terminal differentiation phase. They also require higher insulin concentration during differentiation to enhance lipid accumulation and similar to human primary preadipocytes, PPARy agonist supplementation is also required for ovine adipogenic differentiation. This work highlights species-specific differences requirements for adipogenic differentiation and the need to develop standardized methods to investigate comparative adipocyte biology.

Keywords: Sheep, Fetal, Preadipocyte, Adipogenic differentiation

\section{Biomed Central}

(c) The Author(s). 2017 Open Access This article is distributed under the terms of the Creative Commons Attribution 4.0 International License (http://creativecommons.org/licenses/by/4.0/), which permits unrestricted use, distribution, and reproduction in any medium, provided you give appropriate credit to the original author(s) and the source, provide a link to the Creative Commons license, and indicate if changes were made. The Creative Commons Public Domain Dedication waiver (http://creativecommons.org/ publicdomain/zero/1.0/) applies to the data made available in this article, unless otherwise stated. 


\section{Introduction}

To study adipogenesis, adipogenic differentiation, and their regulation, investigators often resource to the commercially available preadipocyte cell line 3T3-L1 of murine origin [1]. Results from these studies are not as useful for applications on human health as expected, given the physiological and metabolic differences among species [2]. Human primary cultured cells are the best resource to understand human adipocyte biology in deranged metabolic states [2], but cannot inform about cell events that occur during prenatal life. The developmental origins of health and disease theory is pointing to early life events as one of the contributing factors towards the increased prevalence of metabolic diseases worldwide, including obesity [3-5]. To test hypotheses relative to fetal adipose tissue differentiation and fate and/or the effects of prenatal exposures (chemicals, stress, nutrition) on adult metabolic risk, alternative models are often needed [6]. Other large mammalian species, such as feline and porcine primary cells, have recently been used as alternatives [7, 8]. The sheep is an outstanding animal model to understand how prenatal exposures can affect adult metabolic disease risk [9-12] because, as humans, sheep are a monotocous and precocial species, with majority of organs maturing before birth [13], including the adipose tissue [14]. Identified barriers to the advance of our understanding on adipocyte biology include the great diversity of protocols available for some cell lines and the lack of standardized methods of adipogenic differentiation in other mammalian species [2]. As we demonstrate in this study, standard murine 3T3-L1 differentiation protocols $[15,16]$ are not suitable for ovine preadipocyte adipogenic differentiation.

Adipocyte differentiation is a complex process by which preadipocytes transition into lipid-filled, insulin-responsive adipocytes. Adipocyte fate is controlled by transcription factors, including peroxisome proliferator-activated receptor gamma (PPAR $\gamma$ ), CCAAT/ enhancer-binding proteins (C/EBPs), and sterol regulatory element binding protein (SREBP). Preadipocyte differentiation is routinely initiated by a $48 \mathrm{~h}$ exposure to a basic 3T3-L1 differentiation induction cocktail containing 3-isobutyl-1-methyxantine (IBMX), dexamethasone, and insulin [17]. IBMX regulates C/EBP $\beta$ [18], enhances 3T3L1 differentiation upon longer exposures [15], and alone [19] or in combination with dexamethasone [20], regulates PPAR $\gamma$ activity. PPAR $\gamma$, the master regulator of adipogenesis, cooperates with $\mathrm{C} / \mathrm{EBP \alpha}$ to initiate adipogenic differentiation, is required in human preadipocyte differentiation [21, 22], and can increase glycerol-3-phosphate dehydrogenase (GPDH) activity in sheep preadipocytes [23], an enzyme involved in lipid biosynthesis. PPAR $\gamma$ agonists, such as thiazolidinediones, have been used to enhance adipogenic differentiation in 3T3-L1 and primary preadipocytes of large mammals $[7,14,17]$. In addition, supplementation with insulin promotes preadipocyte differentiation [24], but the insulin dose is among the most variable media components of 3T3-L1 differentiation protocols [17].

In this work, we aimed to standardize a protocol for effective ovine adipogenic differentiation using fetal and adult primary cultured preadipocyte that will help understand basic adipocyte biology knowledge in a relevant meat-producing species, as well as events occurring during fetal adipose tissue remodeling. To enable ovine adipogenic differentiation, we applied several media modifications. Here, we have only presented the key modifications that resulted in significant improvements in ovine preadipocyte adipogenic differentiation. 


\section{Materials and methods}

\section{Fetal and adult tissue harvest}

All procedures used in this study were approved by the Institutional Animal Care and Use Committee of Michigan State University (MSU) and are consistent with the National Research Council's Guide for the Care and Use of Laboratory Animals and the Animal Welfare Act. The study was conducted at the MSU Research Facility (East Lansing, MI; $42.7^{\circ} \mathrm{N}, 84.4^{\circ} \mathrm{W}$ ) using an in-house flock of multiparous Polypay $\mathrm{x}$ Dorsett breed of sheep. Female sheep were bred using a time mated pregnancy strategy. At gestational day 120 and after humane sacrifice, fetal perirenal adipose tissue and skin from the abdominal midline were harvested from female fetuses to isolate fetal ovine preadipocytes (oPADs) and skin fibroblasts. Immediately after, tissues were placed in transport medium (Omental Preadipocyte Medium, Zen Bio, USA) and processed within two hours. Adipose tissue was also collected from the subcutaneous adipose depot of three adult females after humane sacrifice.

\section{Generation of fetal and adult ovine primary preadipocytes}

Preadipocyte isolation method was conducted following a common standard protocol used in isolation of human adipogenic precursor cells [25]. This isolation protocol followed by adipogenic differentiation allows an average cell differentiation rate of 50-60\% [25]. In brief, fetal and adult oPADs were isolated by rinsing a 1-2 g of adipose tissue with pre-warmed Dulbecco's phosphate-buffered saline (DPBS) with antibiotic-antimycotic (Invitrogen), removing any visible blood clots and connective tissue using sterile forceps and then minced into small pieces. Collagenase-I (C0130, Sigma, $1 \mathrm{mg} / \mathrm{ml}$ ) was used to digest tissue for $40 \mathrm{~min}$ in a $37^{\circ} \mathrm{C}$ water bath. The mixture was filtered through a mesh filter (250 $\mu \mathrm{m}$, U-CMYBK-250, Component Supply Company, Fort Meade, USA) and centrifuged at $1,200 \mathrm{rpm}$ for $5 \mathrm{~min}$. The cell pellet was washed with fresh omental preadipocyte medium and seeded into 6-well plates. After six days of culture, cells were frozen (Preadipocyte Cryopreservation Medium, FM-1-100, Zen-Bio) and stored in liquid nitrogen until further use. All experiments were performed using fetal oPAD primary cells (passage 3 ) from one female and validated with fetal and adult oPADs from 2 and 3 additional females, respectively. The 3T3-L1 (preadipocyte) and NIH3T3 (fibroblastic) cell lines were used as positive and negative control of adipogenic cells, respectively. Ovine fetal primary fibroblasts were also used as a negative control of adipogenesis.

\section{Generation of fetal ovine primary skin fibroblasts}

Ovine fetal primary fibroblasts were isolated as follows. After hair and connective tissue removal using sterile forceps, fetal skin tissue was rinsed twice with pre-warmed DPBS supplemented with antibiotic and antimycotic. Tissue $(1 \mathrm{~g})$ was minced into small pieces and distributed into 6-well plates with $0.2 \mathrm{ml}$ of serum per well. After $6 \mathrm{~h}$ incubation, $2 \mathrm{ml}$ of basal medium consisting of DMEM/F12 medium (Invitrogen) supplemented with 1\% penicillin-streptomycin, $10 \mathrm{mM}$ HEPES, and 10\% fetal bovine serum (Corning, Manassas, VA, USA) was added into the plate and primary cells cultured for 4 to 6 days until confluency. Cells were then trypsinized and passaged as primary fibroblasts for further study. 


\section{Ovine primary preadipocytes proliferation}

Primary cultured oPADs were trypsin digested (Invitrogen, 0.05\%) for subculture upon 90\% confluency. Proliferation ability for each cultured cell (passage 3) was assessed by growth curve analysis. Cells were seeded at a density of 10,000 cells per well in 24-well plates and the counts were performed in haemocytometer chamber. Cell counts were performed every $24 \mathrm{~h}$ for 8 days. Triplicate wells for each time point per cultured cell were used.

\section{Cell culture and adipocyte differentiation}

Before differentiation induction, fetal oPADs (passage 3), 3T3-L1 cells (American Type Culture Collection, ATCC, Manassas, VA, USA; within passage 6), and NIH-3T3 (ATCC, Manassas, VA, USA; within passage 6) were cultured in basal medium (same as for oSFs) until confluency and allowed to grow for two additional days. Thereafter, adipocyte differentiation was induced. Summary of adipogenic differentiation media and exposure times are detailed in Figs. 1c and 2c. 3T3-L1 differentiation medium 1a (DM1a) consisted of basal medium supplemented with biotin $(33 \mu \mathrm{M})$, pantothenate (17 $\mathrm{mM})$, insulin $(1 \mu \mathrm{g} / \mathrm{ml})$, dexamethasone $(1 \mu \mathrm{M})$ and 3-isobutyl-1-methylxanthine (IBMX, 0.5 mM). 3T3-L1 differentiation medium 1b (DM1b) was same as DM1a, without dexamethasone and IBMX. 3T3-L1 were exposed to DM1a from days 0 to 2 and to DM1b from days 3 to 8 (Fig. 1c). All media were replaced every $48 \mathrm{~h}$. Composition of the modified differentiation medium 2a (DM2a) was the same as DM1a, but supplemented with increased insulin concentration $(10 \mu \mathrm{g})$ and rosiglitazone $(20 \mu \mathrm{M})$. Differentiation medium 2b (DM2b) was the same as DM2a, but without dexamethasone, IBMX, and rosiglitazone (Fig. 2c). Rosiglitazone concentration was based on previous reports [26] and pilot work in our laboratory (data not shown). Ovine female fetal skin fibroblasts were induced to differentiate using the final differentiation protocol to demonstrate how ovine fetal fibroblasts lack the ability to differentiate upon exposure to the PPARY agonist, rosiglitazone (Fig. 3c). 3T3-L1 and NIH-3T3 cell lines were also induced to differentiate (Fig. 3c) in DM1a media for 2 days, following by DM1b media for additional 6 days.

\section{Oil Red O stain}

Preadipocyte differentiation into mature adipocytes was determined by Oil Red O (ORO) stain, as a marker of lipid accumulation. In brief, ORO $(0.3 \%)$ was dissolved in isopropanol diluted in water $(0.18 \%)$. Adipocytes at differentiation day 8 , were washed with DPBS twice then fixed in 10\% formalin for $30 \mathrm{~min}$ at room temperature. Cells were washed with DPBS and incubated $5 \mathrm{~min}$ in 60\% isopropanol followed by incubation in ORO working solution. After multiple DPBS washes, bright field images were captured on an inverted microscope. Five images of each treatment were used to calculate ORO positive area using the Image J software [27].

\section{Quantitative real time PCR (qRT-PCR)}

To evaluate the dynamic expression of genes involved in adipogenic differentiation, qRT-PCR (ABI-Quant Studio 7 Flex Real-Time PCR System, Thermo Fisher, Carlsbad, CA) was performed to examine the mRNA expression of ovine genes encoding for 


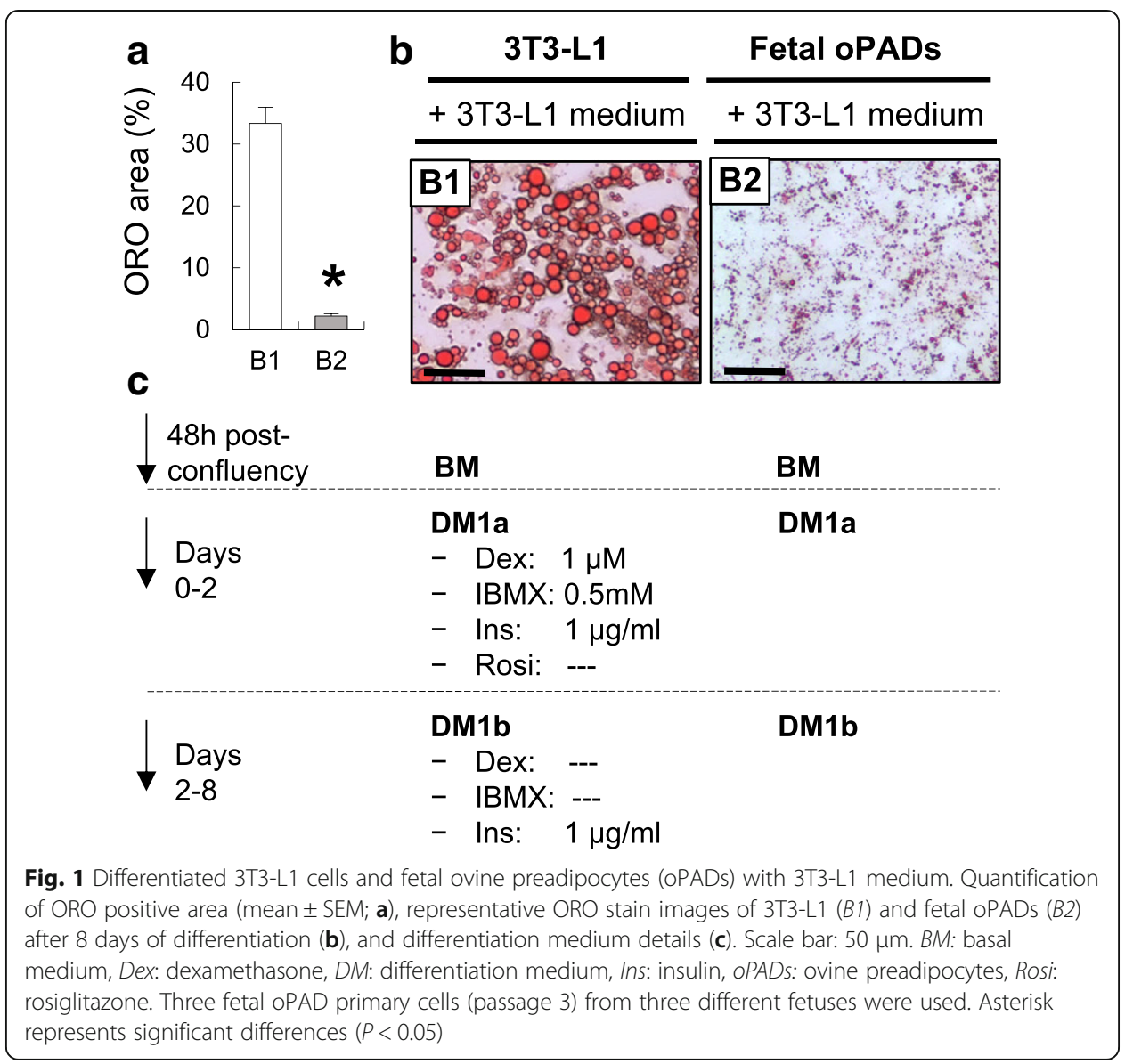

peroxisome proliferator-activated receptor gamma (PPAR ), fatty acid binding protein $4(F A B P 4)$, CCAAT/enhancer-binding protein alpha $(C / E B P \alpha)$, adiponectin (ADIPOQ), protein delta homolog 1 (DLK1) and zinc finger protein 423 (ZFP423). Primer sequences are shown in Table 1 . The sizes of the DNA templates were confirmed by $1.5 \%$ agarose gel. Cultured cells were washed three times with ice cooled DPBS and total RNA extracted with an RNeasy Mini kit (Qiagen, Hilden, Germany) according to the manufacturer's protocol. RNA quality and concentration were measured by Nanodrop (Thermo Fisher Science, Wilmington, NC, USA). $1 \mu \mathrm{g}$ RNA (quality: A260/A280: $2.0 \pm 0.05$; concentration: $200 \pm 50 \mathrm{ng} / \mu \mathrm{l}$ ) was reverse transcribed into cDNA using a High Capacity cDNA Reverse Transcription Kit (Promega, Madison, WI, USA) in $10 \mu \mathrm{l}$ reaction volume. cDNA amplification reaction $(50 \mathrm{ng}$ ) consisted of template denaturation and polymerase activation at $95{ }^{\circ} \mathrm{C}$ for $30 \mathrm{~s}$, followed by 40 cycles of denaturation at $95{ }^{\circ} \mathrm{C}$ for $15 \mathrm{~s}$, annealing at $60{ }^{\circ} \mathrm{C}$ for $30 \mathrm{~s}$, and extension at $72{ }^{\circ} \mathrm{C}$ for $30 \mathrm{~s}$. All experiments and qRT-PCR were run in triplicate. Melt curve analyses were performed for all genes, and the specificity as well as integrity of the PCR products was confirmed by the presence of a single peak. The levels of mRNA encoding the indicated genes were normalized against three housekeeping genes GAPDH, RPL27, and $\beta$-actin to calculate relative fold change to that of the control. Results using all three housekeeping genes provided with the same results, but only GAPDH data are shown. 


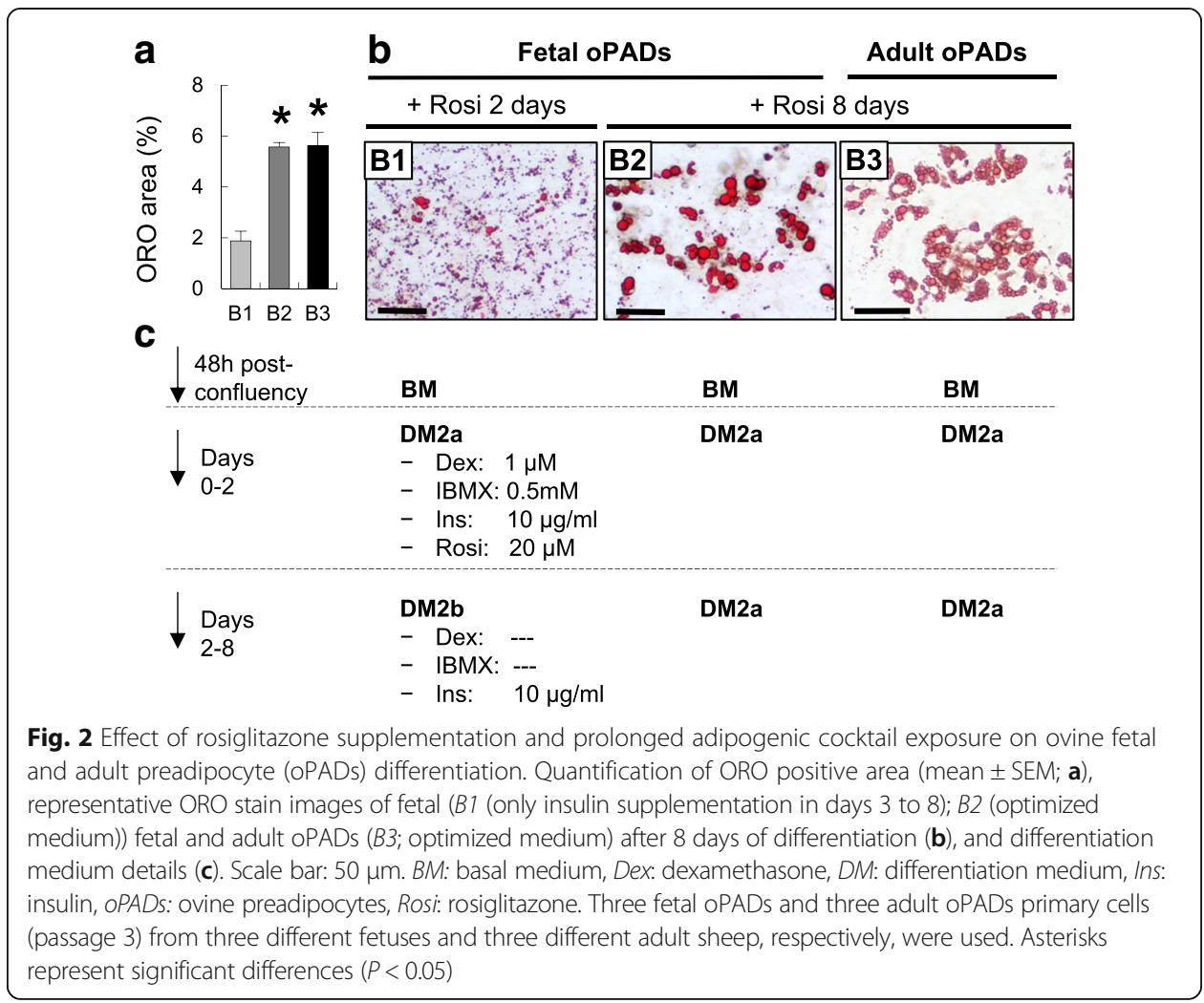

\section{Statistics}

All data are presented as mean \pm SEM. All experiments (adipogenic differentiation in fetal and adult oPADs and oSFs, and qRT-PCR) were conducted in triplicate. Appropriate transformations were applied, as needed, to account for normality of data. ANOVA was used to compare gene expression data among differentiation time points followed by Dunnett's posthoc test. For comparing percent differences Fisher's exact test was used. Statistical software used was PASW Statistics for Windows release 18.0.1. Differences were considered significant at $P<0.05$.

\section{Results and discussion}

In this work, we have successfully established a protocol to induce adipogenic differentiation in fetal and adult ovine primary cultured preadipocytes. As expected from preadipocytes, the morphology of oPADs was phenotypically fibroblastic (Fig. 4a-b), demonstrated good proliferative ability (Fig. 4c), and expressed both, the preadipocyte marker (DLK1) [28] and the adipogenic differentiation ability marker (ZFP423) [29] mRNA (Fig. 3a). ZFP423 mRNA expression was highest in the 3T3-L1 cell line (100\%, preadipocyte cell line), followed by oPADs (71\%), ovine fetal primary fibroblasts (17\%) and NIH-3T3 cell line (0.5\%, fibroblast cell line) and was positively correlated with the differentiation ability of each of these cultured cells and cell lines (Fig. 3b-c).

We first tested the ability of the 3T3-L1 differentiation protocol (Fig. 1c) to induce differentiation in fetal oPADs and compared it to the differentiation ability in the 3T3-L1 cell line (Fig. 1). After 8 days of differentiation, over 90\% of 3T3-L1 cells differentiated in fully mature adipocytes as shown by ORO stain (Fig. 1a and b1). However, the 3T3-L1 protocol 


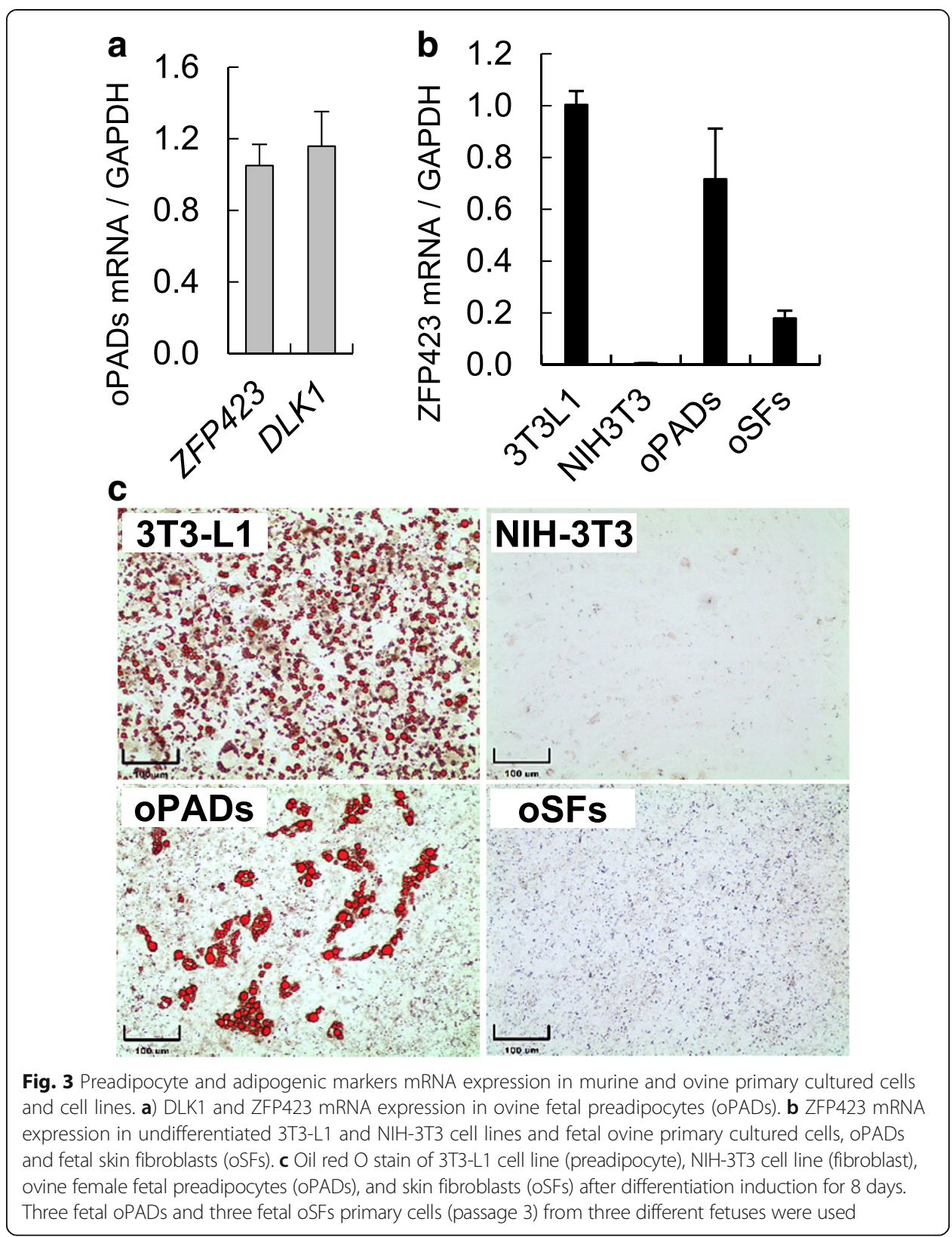

was not able to induce terminal adipogenic differentiation in oPADs (Fig. 1a and b2). The $\geq 16$-fold difference between 3T3-L1 and fetal oPADs differentiation was similar to reports standardizing adipogenic differentiation with human primary preadipocytes [22, 30].

Because insulin concentration is among the adipogenic media supplements with the largest variation [17], we tested if increasing the insulin concentration would improve accumulation of lipid droplets during adipogenic differentiation. A 10-fold increase in insulin concentration $(10 \mu \mathrm{g} / \mathrm{ml})$ induced the formation of small and middle-sized lipid droplets in fetal oPADs (data not shown). 3T3-L1 cells do not require adipogenic induction with a PPAR $\gamma$ agonist, however differentiation protocols for large mammalian species $[7,8,14]$ preadipocyte and human mesenchymal stem cells into adipocytes often include this modification [31,32]. To test if supplementation with a PPAR $\gamma$ 
Table 1 Primers for quantitative real time PCR

\begin{tabular}{|c|c|c|c|}
\hline Gene & Primer & Length (bp) & Accession number \\
\hline$O A D I P O Q$ - Forward & GGAGATCCAGGTCTCGTTGG & 98 & NM_001308565 \\
\hline OADIPOQ - Reverse & TTCTGCCTGGGACTCCTGG & & \\
\hline oß-ACTIN - Forward & CCAACCGTGAGAAGATGACC & 97 & NM_001009784 \\
\hline oß-ACTIN - Reverse & CCAGAGGCGTACAGGGACAG & & \\
\hline oC/EBPa - Forward & CCCCGACAGGAGCAAGGT & 114 & KF830871 \\
\hline oC/EBPa-Reverse & GGTTCAAAGCCCCAAGT & & \\
\hline oDLK1 - Forward & GGCATCGTCTTCCTCAAC & 89 & XM_015102053 \\
\hline oDLK1 - Reverse & CGCAGCAGCAGATTCTTC & & \\
\hline OFABP4 - Forward & GGATGATAAGCTGGTGCTGG & 53 & NM_001114667.1 \\
\hline oFABP4 - Reverse & CTCTGGTAGCAGTGACACCG & & \\
\hline OGAPDH - Forward & TTCCACGGCACAGTCAA & 241 & NM_001190390 \\
\hline oGAPDH - Reverse & TCACGCCCATCACAAAC & & \\
\hline mGAPDH - Forward & CGGCAAATTCAACGGCACA & 84 & NM_001289726 \\
\hline mGAPDH - Reverse & TCTCGCTCCTGGAAGATGG & & \\
\hline OPPARY - Forward & TGGATGACCACTCCCATGCC & 97 & NM_001100921 \\
\hline oPPARY - Reverse & TTGGGAACGGAATGTCCTC & & \\
\hline oRPL27 - Forward & CGCAAGGCCCGACGAGAGGC & 93 & XM_015098799 \\
\hline oRPL27 - Reversr & GACCTAAAACCGCAGCTTCTGG & & \\
\hline oZFP423 - Forward & CCCGATTCCAGCAACCACA & 160 & XM_015100428 \\
\hline oZFP423 - Reverse & CGTCATCCCGCATCTTCTTCT & & \\
\hline mZFP423 - Forward & CCGTCTGCTTCACAGTCTTCG & 155 & NM_001310520 \\
\hline mZFP423 - Reverse & TGCGTGCTGGCTCATCG & & \\
\hline
\end{tabular}

Note: o refers to ovine, $m$ refers to murine. Accession number from NCBI gene database

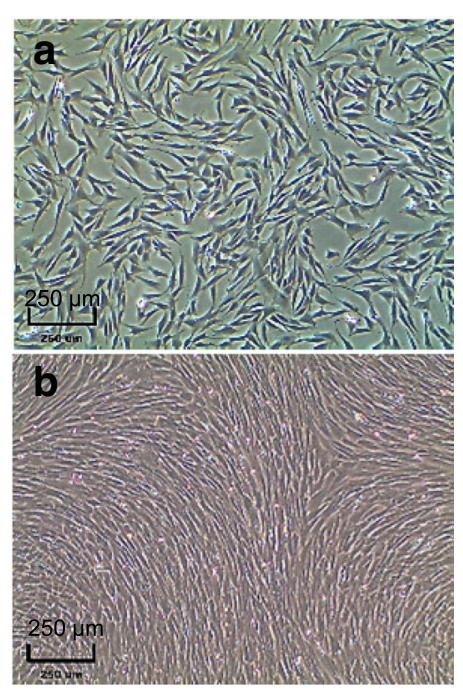

C

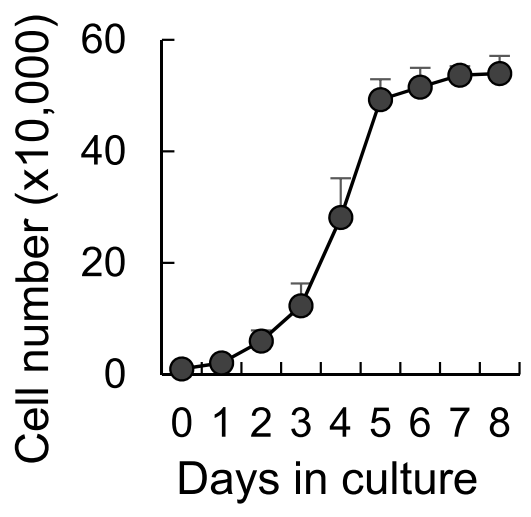

Fig. 4 Characterization of primary fetal ovine preadipocytes (OPADs). oPADs in culture (a) and at confluency (b). c Preadipocytes growth curve (mean \pm SEM) over 8 days (three fetal oPADs cell lines) 


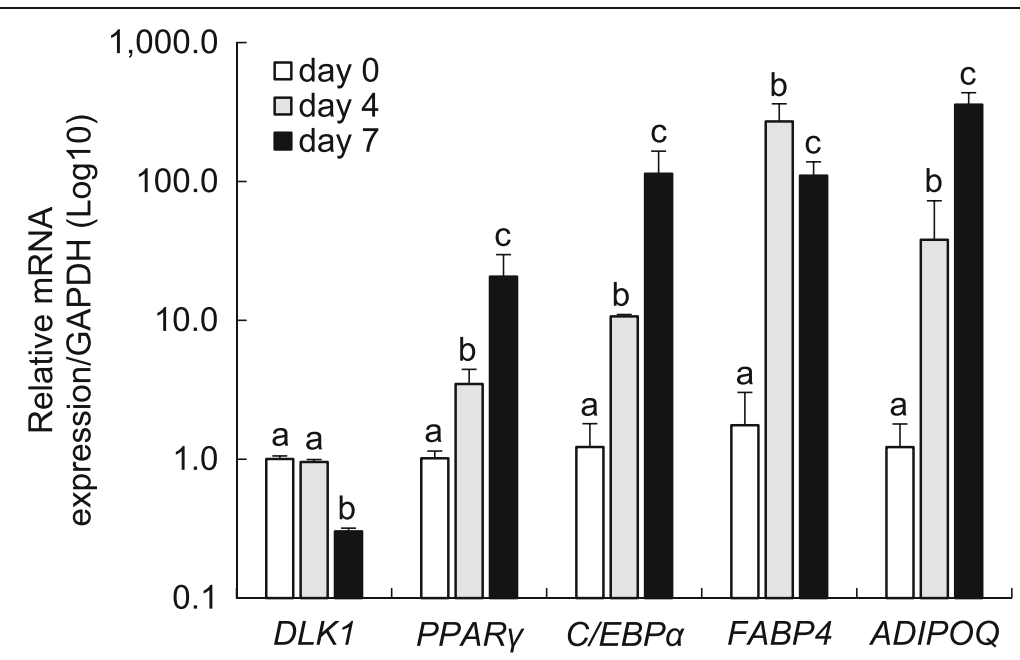

Fig. 5 Dynamic gene expression in fetal ovine preadipocytes (OPADs) during differentiation. mRNA expression (mean \pm SEM) through adipogenic differentiation in fetal oPADs from day 0 to 7 of differentiation when using the optimized differentiation protocol (Fig. 2b2). Different letters represent significant differences $(P<0.05)$ within gene and between culture days by ANOVA. Three fetal oPAD primary cells (passage 3) from three different fetuses were used. Gene expression was validated using three housekeeping genes (GAPDH, RPL27, and $\beta$-actin), but only GAPDH results are shown

agonist results in enhanced fetal ovine preadipocyte differentiation, rosiglitazone was selected over other PPAR $\gamma$ agonists, such as troglitazone, because troglitazone is only a partial PPAR $\gamma$ agonist [33]. Rosiglitazone $(20 \mu \mathrm{M})$ was included into the differentiation medium (DM2a; Fig. 2c) and cells exposed for 2 days. Thereafter, differentiation medium was replaced with DM2b (Fig. 2c) and fetal oPADs cultured for 6 additional days. Addition of a PPAR $\gamma$ agonist for $48 \mathrm{~h}$ improved differentiation, increasing medium-sized lipid droplet formation (Fig. 2b1) and suggesting that similar to feline [7], porcine [34], and human [31] preadipocytes, ovine preadipocytes have lower sensitivity to insulin than murine cell lines and PPAR $\gamma$ agonist may be a more stringent requirement for adipogenic differentiation in these species.

Since previous studies have shown that longer exposure ( $>2$ days) to the differentiation cocktail can enhance adipogenesis $[35,36]$, we tested if a longer exposure to the DM2a increased ovine adipogenic differentiation. Exposure to the DM2a for 8 days resulted in an enhanced adipogenic differentiation of oPADs and formation of medium to large sized lipid droplets (Fig. 2b2). With this differentiation protocol, lipid accumulation is readily visible under light microscope starting at day 3 of culture. The final protocol (8 days of DM2a exposure) was tested in two additional fetal oPADs confirming differentiation results observed in the first fetal oPAD cultured cells. We also tested our optimized adipogenic differentiation system in three different ovine adult primary cultured preadipocytes. Adult subcutaneous preadipocytes were used and a similar differentiation rate to that seen in fetal oPADs was observed (Fig. 2a and b3). Because PPAR $\gamma$ agonists can induce lipid droplet accumulation in non-adipogenic cells, we used ovine fetal skin fibroblasts to test if rosiglitazone could induce lipid droplet accumulation. Fetal fibroblasts originated from the same animals as the oPADs. When subjected to the final protocol (DM2a for 8 days), fetal fibroblasts were not able to accumulate lipid droplets (Fig. 3c). 
To further assess the differentiation process in oPADs, we evaluated the expression of genes expressed in preadipocytes $(D L K 1)$ and in the commitment $(C / E B P \alpha$ and $P P A R \gamma$ ) and terminal phase (FABP4 and $A D I P O Q$ ) of adipogenesis by qRT-PCR. Differentiation was confirmed by a downregulation of $D L K 1$ and exponential upregulation of $C / E B P \alpha, P P A R \gamma, F A B P 4$, and $A D I P O Q$ (Fig. 5) upon differentiation progression.

In conclusion, our protocol enables successful adipogenic differentiation of fetal and adult ovine preadipocytes. It also demonstrates that compared to the 3T3-L1 cell line, fetal ovine preadipocytes require a longer exposure to the differentiation cocktail, and suggests the need for IMBX, dexamethasone, and/or the PPARY agonist rosiglitazone through the terminal differentiation phase. They also require higher insulin concentration during differentiation to enhance lipid accumulation and similar to human primary preadipocytes [21, 22], PPAR $\gamma$ agonist supplementation is also required for ovine adipogenic differentiation. This work highlights species-specific differences requirements for adipogenic differentiation $[7,14,31,34]$ and the need to develop standardized methods to investigate comparative adipocyte biology.

\begin{abstract}
Abbreviations
ADIPOQ: adiponectin; ATCC: American Type Culture Collection; BS: Basal medium; C/EBP: CCAAT/enhancer-binding protein; Dex: Dexamethasone; DLK1: Delta like non-canonical Notch ligand 1; DM: Differentiation medium;

DMEM: Dulbecco's modified Eagle's medium; DPBS: Dulbecco's phosphate-buffered saline; FABP4: Fatty acid binding protein 4; GAPDH: Glyceraldehyde 3-phosphate dehydrogenase; GPDH: Glycerol-3-phosphate dehydrogenase; IBMX: 3isobutyl-1-methylxanthine; Ins: Insulin; OPAD: Ovine fetal preadipocytes; ORO: Oil Red O; PPARY: Peroxisome proliferatoractivated receptor Y; qRT-PCR: Quantitative real time PCR; Rosi: Rosiglitazone; ZFP423: Zinc finger protein 423
\end{abstract}

\title{
Acknowledgements
}

We thank the support of the Michigan State University Sheep Teaching and Research Farm and the technical help of Mr. Jeremy Gingrich and Dr. Steve Suhr.

\section{Funding}

This research was supported by Michigan State University (MSU) General Funds, AgBio Research and the United States Department of Agriculture (USDA) National Institute of Food and Agriculture, Hatch project MICL02383, and 1 K22ES026208 (NIEHS/NIH).

Availability of data and material

Not applicable.

Author's contributions

AV-L and YP conceived the study, carried out the experiments, and analyzed the data. AV-L wrote the manuscript draft and AV-L and YP revised and had final approval of the submitted and published versions.

Competing interests

The authors declare that they have no competing interests.

Consent for publication

Not applicable.

Ethics approval and consent to participate

Not applicable.

\section{Publisher's Note}

Springer Nature remains neutral with regard to jurisdictional claims in published maps and institutional affiliations.

Received: 12 January 2017 Accepted: 10 March 2017

Published online: 23 March 2017

\section{References}

1. Green $\mathrm{H}$, Kehinde O. An established preadipose cell line and its differentiation in culture. II. Factors affecting the adipose conversion. Cell. 1975;5:19-27.

2. Ruiz-Ojeda FJ, Ruperez Al, Gomez-Llorente C, Gil A, Aguilera CM. Cell models and their application for studying adipogenic differentiation in relation to obesity: a review. Int J Mol Sci. 2016. doi:10.3390/ijms17071040. 
3. Huang RC, Prescott SL, Godfrey KM, Davis EA. Assessment of cardiometabolic risk in children in population studies: underpinning developmental origins of health and disease mother-offspring cohort studies. J Nutr Sci. 2015. doi:10.1017/jns.2014.69

4. Benyshek DC. The "early life" origins of obesity-related health disorders: new discoveries regarding the intergenerational transmission of developmentally programmed traits in the global cardiometabolic health crisis. Am J Phys Anthropol. 2013. doi:10.1002/ajpa.22393.

5. Perrone S, Santacroce A, Picardi A, Buonocore G. Fetal programming and early identification of newborns at high risk of free radical-mediated diseases. World J Clin Pediatr. 2016. doi:10.5409/wjcp.v5.i2.172.

6. Chavatte-Palmer P, Tarrade A, Rousseau-Ralliard D. Diet before and during pregnancy and offspring Health: the importance of animal models and what can be learned from them. Int J Environ Res Public Health. 2016. doi:10. 3390/ijerph13060586.

7. Riedel J, Badewien-Rentzsch B, Kohn B, Hoeke L, Einspanier R. Characterization of key genes of the reninangiotensin system in mature feline adipocytes and during in vitro adipogenesis. J Anim Physiol Anim Nutr (Berl). 2015. doi:10.1111/jpn.12392.

8. Pang WJ, Wei N, Wang Y, Xiong Y, Chen FF, Wu WJ, Zhao CZ, Sun SD, Yang GS. Obese and lean porcine difference of FoxO1 and its regulation through C/EBPbeta and PI3K/GSK3beta signaling pathway. J Anim Sci. 2014. doi:10.2527/jas.2013-7098.

9. Padmanabhan V, Veiga-Lopez A, Abbott DH, Recabarren SE, Herkimer C. Developmental programming: impact of prenatal testosterone excess and postnatal weight gain on insulin sensitivity index and transfer of traits to offspring of overweight females. Endocrinology. 2010. doi:10.1210/en.2009-1015.

10. Veiga-Lopez A, Moeller J, Patel D, Ye W, Pease A, Kinns J, Padmanabhan V. Developmental programming: impact of prenatal testosterone excess on insulin sensitivity, adiposity, and free fatty acid profile in postpubertal female sheep. Endocrinology. 2013. doi:10.1210/en.2012-2145.

11. Veiga-Lopez A, Moeller J, Sreedharan R, Singer K, Lumeng C, Ye W, Pease A, Padmanabhan V. Developmental programming: interaction between prenatal BPA exposure and postnatal adiposity on metabolic variables in female sheep. Am J Physiol Endocrinol Metab. 2016. doi:10.1152/ajpendo.00425.2015.

12. Cardoso RC, Veiga-Lopez A, Moeller J, Beckett E, Pease A, Keller E, Madrigal V, Chazenbalk G, Dumesic D, Padmanabhan V. Developmental programming: impact of gestational steroid and metabolic milieus on adiposity and insulin sensitivity in prenatal testosterone-treated female sheep. Endocrinology. 2016. doi:10.1210/en.2015-1565.

13. Padmanabhan V, Veiga-Lopez A. Animal models of the polycystic ovary syndrome phenotype. Steroids. 2013. doi:10.1016/j.steroids.2013.05.004.

14. Hausman GJ, Basu U, Wei S, Hausman DB, Dodson MV. Preadipocyte and adipose tissue differentiation in meat animals: influence of species and anatomical location. Annu Rev Anim Biosci. 2014. doi:10.1146/annurev-animal022513-114211.

15. Hua Y, Ke S, Wang Y, Irwin DM, Zhang S, Wang Z. Prolonged treatment with 3-isobutyl-1-methylxanthine improves the efficiency of differentiating 3T3-L1 cells into adipocytes. Anal Biochem. 2016. doi:10.1016/j.ab.2016.05.007.

16. Zebisch K, Voigt V, Wabitsch M, Brandsch M. Protocol for effective differentiation of 3T3-L1 cells to adipocytes. Anal Biochem. 2012. doi:10.1016/j.ab.2012.03.005.

17. Scott MA, Nguyen VT, Levi B, James AW. Current methods of adipogenic differentiation of mesenchymal stem cells. Stem Cells Dev. 2011. doi:10.1089/scd.2011.0040

18. Yeh WC, Cao Z, Classon M, McKnight SL. Cascade regulation of terminal adipocyte differentiation by three members of the C/EBP family of leucine zipper proteins. Genes Dev. 1995;9:168-81.

19. Hamm JK, Park BH, Farmer SR. A role for C/EBPbeta in regulating peroxisome proliferator-activated receptor gamma activity during adipogenesis in 3T3-L1 preadipocytes. J Biol Chem. 2001. doi:10.1074/jbc.M100797200.

20. Gurriaran-Rodriquez U, Al-Massadi O, Roca-Rivada A, Crujeiras AB, Gallego R, Pardo M, Seoane LM, Pazos Y, Casanueva FF, Camina JP. Obestatin as a regulator of adipocyte metabolism and adipogenesis. J Cell Mol Med. 2011. doi:10.1111/j.1582-4934.2010.01192.x

21. Michaud A, Lacroix-Pepin N, Pelletier M, Daris M, Biertho L, Fortier MA, Tchernof A. Expression of genes related to prostaglandin synthesis or signaling in human subcutaneous and omental adipose tissue: depot differences and modulation by adipogenesis. Mediators Inflamm. 2014. doi:10.1155/2014/451620.

22. Lee MJ, Wu Y, Fried SK. A modified protocol to maximize differentiation of human preadipocytes and improve metabolic phenotypes. Obesity. 2012. doi:10.1038/oby.2012.116.

23. Soret B, Lee HJ, Finley E, Lee SC, Vernon RG. Regulation of differentiation of sheep subcutaneous and abdominal preadipocytes in culture. J Endocrinol. 1999;161:517-24.

24. Klemm DJ, Leitner JW, Watson P, Nesterova A, Reusch JE, Goalstone ML, Draznin B. Insulin-induced adipocyte differentiation. Activation of CREB rescues adipogenesis from the arrest caused by inhibition of prenylation. J Biol Chem. 2001. doi:10.1074/jbc.M103382200.

25. Skurk T, Hauner H. Primary Culture of Human Adipocyte Precursor Cells: Expansion and Differentiation. In: Mitry RR, Hughes RD, editors. Human cell culture protocols. Totowa: Humana Press; 2012. p. 215-26.

26. Contador D, Ezquer F, Espinosa M, Arango-Rodriguez M, Puebla C, Sobrevia L, Conget P. Dexamethasone and rosiglitazone are sufficient and necessary for producing functional adipocytes from mesenchymal stem cells. Exp Biol Med (Maywood). 2015. doi:10.1177/1535370214566565.

27. NIH Image J. Image processing and analysis in Java. 2016. https://imagej.nih.gov/ij/.

28. Sul HS. Minireview: Pref-1: role in adipogenesis and mesenchymal cell fate. Mol Endocrinol. 2009. doi:10.1210/me.2009-0160

29. Gupta RK, Mepani RJ, Kleiner S, Lo JC, Khandekar MJ, Cohen P, Frontini A, Bhowmick DC, Ye L, Cinti S, Spiegelman BM. Zfp423 expression identifies committed preadipocytes and localizes to adipose endothelial and perivascular cells. Cell Metab. 2012. doi:10.1016/j.cmet.2012.01.010.

30. Hemmrich K, von Heimburg D, Cierpka K, Haydarlioglu S, Pallua N. Optimization of the differentiation of human preadipocytes in vitro. Differentiation. 2005. doi:10.1111/j.1432-0436.2005.07301003.x.

31. Patel NG, Holder JC, Smith SA, Kumar S, Eggo MC. Differential regulation of lipogenesis and leptin production by independent signaling pathways and rosiglitazone during human adipocyte differentiation. Diabetes. 2003;2:43-50. 
32. Ninomiya Y, Sugahara-Yamashita Y, Nakachi Y, Tokuzawa Y, Okazaki Y, Nishiyama M. Development of a rapid culture method to induce adipocyte differentiation of human bone marrow-derived mesenchymal stem cells. Biochem Biophys Res Commun. 2010. doi:10.1016/j.bbrc.2010.03.001.

33. Camp HS, Li O, Wise SC, Hong YH, Frankowski CL, Shen XQ, Vanbogelen R, Leff T. Differential activation of peroxisome proliferator-activated receptor-gamma by troglitazone and rosiglitazone. Diabetes. 2000;49(4):539. doi:10.2337/diabetes.

34. Bohan AE, Purvis KN, Bartosh JL, Brandebourg TD. The proliferation and differentiation of primary pig preadipocytes is suppressed when cultures are incubated at 37 degrees Celsius compared to euthermic conditions in pigs. Adipocyte. 2014. doi:10.4161/21623945.2014.981434.

35. Lessard J, Laforest S, Pelletier M, Leboeuf M, Blackburn L, Tchernof A. Low abdominal subcutaneous preadipocyte adipogenesis is associated with visceral obesity, visceral adipocyte hypertrophy, and a dysmetabolic state. Adipocyte. 2014. doi:10.4161/adip.29385.

36. Hwang S, Byun JW, Yoon JS, Lee EJ. Inhibitory effects of alpha-Lipoic acid on Oxidative stress-induced adipogenesis in orbital fibroblasts from patients with graves ophthalmopathy. Medicine (Baltimore). 2016. doi:10.1097/MD.0000000000002497.

Submit your next manuscript to BioMed Central and we will help you at every step:

- We accept pre-submission inquiries

- Our selector tool helps you to find the most relevant journal

- We provide round the clock customer support

- Convenient online submission

- Thorough peer review

- Inclusion in PubMed and all major indexing services

- Maximum visibility for your research

Submit your manuscript at www.biomedcentral.com/submit 